\title{
Thrombophilia, Thrombosis and Thromboprophylaxis in Pregnancy: For What and in Whom?
}

\author{
Saskia Middeldorp ${ }^{1}$ Christiane Naue ${ }^{2}$ Christina Köhler ${ }^{2}$ \\ ${ }^{1}$ Department of Internal Medicine, Radboud Institute of Health \\ Sciences (RIHS), Radboud University Medical Center, Nijmegen, The \\ Netherlands \\ 2 Division of Hematology, Department of Medicine I, University \\ Hospital "Carl Gustav Carus" Dresden, Dresden, Germany \\ Address for correspondence Saskia Middeldorp, Radboudumc, \\ Postbus 9101, 6500 HB Nijmegen (Huispost/Looproute 463), Geert \\ Grooteplein 10, Nijmegen, 6525 GA, The Netherlands \\ (e-mail: Saskia.middeldorp@radboudumc.nl).
}

Hamostaseologie 2022;42:54-64.

\begin{abstract}
Keywords

- venous thromboembolism

- thrombophilia

- pregnancy complications

- low-molecular-weight heparin

Compared with nonpregnant women, pregnancy carries a four- to fivefold higher risk of venous thromboembolism (VTE). Despite increasing use of heparin prophylaxis in identified high-risk patients, pulmonary embolism still is the leading cause of maternal mortality in the western world. However, evidence on optimal use of thromboprophylaxis is scarce. Thrombophilia, the hereditary or acquired tendency to develop VTE, is also thought to be associated with complications in pregnancy, such as recurrent miscarriage and preeclampsia. In this review, the current evidence on optimal thromboprophylaxis in pregnancy is discussed, focusing primarily on VTE prevention strategies but also discussing the potential to prevent recurrent pregnancy complications with heparin in pregnant women with thrombophilia.
\end{abstract}

\section{Introduction}

Venous thromboembolism (VTE) is the third most common acute cardiovascular disease ${ }^{1}$ and comprises deep vein thrombosis (DVT) and pulmonary embolism (PE). It occurs with an incidence of approximately 1 to 2 per 1,000 annually in the general population with increasing tendency. ${ }^{1-5}$ Rates differ among age groups and sex. Although the incidence is approximately 1 per 10,000 in individuals younger than 40 years, the rate rises rapidly up to 1 per 100 annually in the elderly. Although men have an intrinsically slightly higher risk of VTE and VTE recurrence, ${ }^{6}$ women are at higher risk during fertile age due to transient risk factors, such as use of hormonal contraception or pregnancy and puerperium. During pregnancy, women are up to five times more likely to develop VTE when compared with age-matched non-pregnant women. ${ }^{7-10}$

\section{Venous Thromboembolism and Pregnancy}

Approximately 1 to 2 per 1,000 pregnant women are affected by venous thromboembolic complications. ${ }^{11-13}$ Within

received

November 22, 2021

accepted after revision

December 8, 2021

pregnancy-related VTE, DVT accounts for approximately 75 to $80 \%$ of all VTE cases and some 20 to $25 \%$ manifest as PE. ${ }^{8}$ The risk presents from the beginning of the first trimester, but with increasing pregnancy duration the risk continuously increases, with highest risk in the early postpartum period. Here, a 15- to 35-fold increase in the risk of VTE compared with nonpregnant, age-matched population has been reported, ${ }^{14}$ whereas others have estimated up to 84 fold risk increase within the first 6 weeks of puerperium. ${ }^{7,15,16}$ As a result, half of pregnancy-associated PE and approximately one-third of DVT strikes after delivery underlining the persistent high-risk postpartum. The risk starts to decline rapidly after 6 weeks postpartum ${ }^{14,17}$ with a return to baseline risk after approximately 12 weeks postnatally. Maternal death due to VTE during pregnancy and puerperium accounts for approximately $14 \%$ of peripartum deaths in developed countries, only surpassed by hemorrhage (16.3\%), resulting in approximately 1 per 100,000 pregnant women dying of pregnancy-related VTE. ${ }^{8,18-20}$ Pelvic vein and iliofemoral vein thrombosis, uncommon outside of pregnancy, constitute a high proportion of pregnancy-related VTE. DVT

(c) 2022. Thieme. All rights reserved. Georg Thieme Verlag KG,

Rüdigerstraße 14,

70469 Stuttgart, Germany
DOI https://doi.org/ 10.1055/a-1717-7663. ISSN 0720-9355. 
in pregnancy occurs more proximal and more often in the left leg. A review in 2010 observed 71\% isolated proximal DVTs without manifestation in the distal veins and a proportion of $17 \%$ of isolated iliac vein thrombosis during pregnancy. ${ }^{21}$ Importantly, isolated proximal DVT (i.e., without involvement of the calf veins) is common during pregnancy and is important for diagnostic considerations. Since pregnancyrelated DVT occurs at a young age, and because of the proximal location of many of these DVTs, long-term consequences are very common. If postthrombotic syndrome complicates the clinical course, this has a very negative impact on quality of life. ${ }^{22}$ The impact on quality of life depends on the severity of the postthrombotic syndrome. Fortunately, severe postthrombotic syndrome is a rare condition but still occurs in up to approximately $7 \%$ of pregnancy-related VTE. ${ }^{23-25}$

\section{Pregnancy-Related Physiological Changes to Coagulation Factors}

Virchow's classic triad for VTE-hypercoagulability, venous stasis, and vascular damage-occurs in an uncomplicated course of pregnancy and delivery.

During pregnancy, the body is exposed to major hemodynamic and hemostatic changes that result in a procoagulant state. In response to a higher bleeding risk in pregnancy and especially during delivery and the early puerperium period, the body shifts to a hypercoagulable state: plasma levels of procoagulant factors are elevated (such as coagulant factors VII, VIII, X, fibrinogen, and von Willebrand factor) and anticoagulant activity decreases with a resulting physiological inhibitor deficiency (reduced levels of protein $S$ and acquired resistance to activated protein C). Furthermore, the activity of the fibrinolytic system is reduced due to decreased activity of tissue plasminogen activator as well as increased levels of plasminogen activator inhibitors. Moreover, hemodynamic changes (namely, progesteroneinduced vasodilatation, mechanical compression of inferior vena cava and iliac veins by the enlarging gravid uterus) and delivery or venous hypertension-associated vascular injury contribute to the increased risk of VTE.

\section{Personal History of Venous Thromboembolism}

Likely the strongest individual risk factor for women experiencing pregnancy-related VTE is a personal history of DVT and/or PE. Pregnant women with previous venous thrombosis are at a 3.5-fold higher risk to suffer from VTE recurrence during pregnancy than outside the pregnancy with an estimated absolute risk of recurrence of 6 to $10 \%$ if no heparin thromboprophylaxis is applied. ${ }^{26}$

The circumstances and number of previous VTE influence the VTE recurrence risk during pregnancy and puerperium. Previous VTE events associated with hormone treatment or previous pregnancies are associated with a higher risk of recurrence in a subsequent pregnancy than prior VTE events that were unprovoked or provoked by transient, non-hor- mone-related risk factors (i.e., trauma, surgery, immobility). De Stefano et $\mathrm{al}^{27}$ performed a retrospective cohort analysis in 1,104 women with prior single DVT or isolated PE to evaluate the VTE recurrence risk during pregnancy and puerperium without antithrombotic prophylaxis. They identified 155 pregnancies and 120 postnatal periods without thromboprophylactic intervention. In women with a previously unprovoked VTE or a VTE related to pregnancy or oral contraceptive use, the VTE recurrence rate was 7.5\% (95\% confidence interval [CI]: 4.0-13.7). In contrast, if the index VTE was neither unprovoked, nor related to pregnancy and not associated with oral contraceptive use, no recurrences of VTE during pregnancy were observed. During puerperium, risks of recurrent VTE were $15.5 \%$ in women with a pregnancy-related prior VTE (95\% CI: 7.7-28.7); 7.1\% (95\% CI: 1.922.6 ) in the group with nonhormonal transient risk factors and 3.1\% (95\% CI: 0.5-15.7) in women with a prior unprovoked VTE. Thus, recurrence risk was nearly fourfold elevated in women who experienced a first pregnancy-associated VTE. The risk of recurrence is also elevated in pregnancies following a previously unprovoked VTE. ${ }^{28}$

\section{Individual Risk Factors for Venous Thromboembolism}

Besides the direct pregnancy-related anatomical and hemostatic changes and the impact of a previous VTE, several additional individual factors enhance the risk for VTE in pregnancy (-Fig. 1). Risk factors for VTE in pregnancy include anthropometric characteristics, acute or chronic illness, as well as pregnancy-related and obstetric complications (-Table 1 ).

For example, obesity with pre-pregnancy body mass index (BMI) greater than $30 \mathrm{~kg} / \mathrm{m}^{2}$ is associated with elevated VTE risk in pregnancy (adjusted OR: 9.7; 95\% CI: 3.1-30.8) and postpartum (adjusted OR: 2.8 ; $95 \% \mathrm{Cl}: 0.8-9.8$ ). ${ }^{29}$ Blondon et $\mathrm{al}^{30}$ considered the pre-pregnancy BMI as appropriate tool with a linear association regarding the postpartum VTE risk. The highest risk was found in severely obese women with increased postpartum VTE risk up to fourfold (prepregnancy BMI $\geq 40 \mathrm{~kg} / \mathrm{m}^{2}$; OR: 4.0 (95\% CI: 2.7-6.3).

Furthermore, immobilization of more than 7 days, especially in combination with obesity and hospital admission, is a relevant risk factor.

Ovarian stimulation for in vitro fertilization doubles VTE risk, but the absolute risk is low $(0.1-0.3 \%$ per approach). ${ }^{31-33}$ However, women with severe ovarian hyperstimulation syndrome (OHSS) are at a substantially increased risk (up to 100 -fold relative risk; absolute risk: $1-4 \%$ ) of developing VTE events.

Caesarean section is associated with two- to fourfold increase of thromboembolic risk, which translates to an average of 3 VTEs out of 1,000 performed interventions and depends on several issues: elective C-section has a lower VTE risk in comparison to emergency caesarean sections. ${ }^{34}$

Currently, there are no universally accepted validated risk scores. There are only few scores with limited validity for individual risk stratification in pregnancy and puerperium 


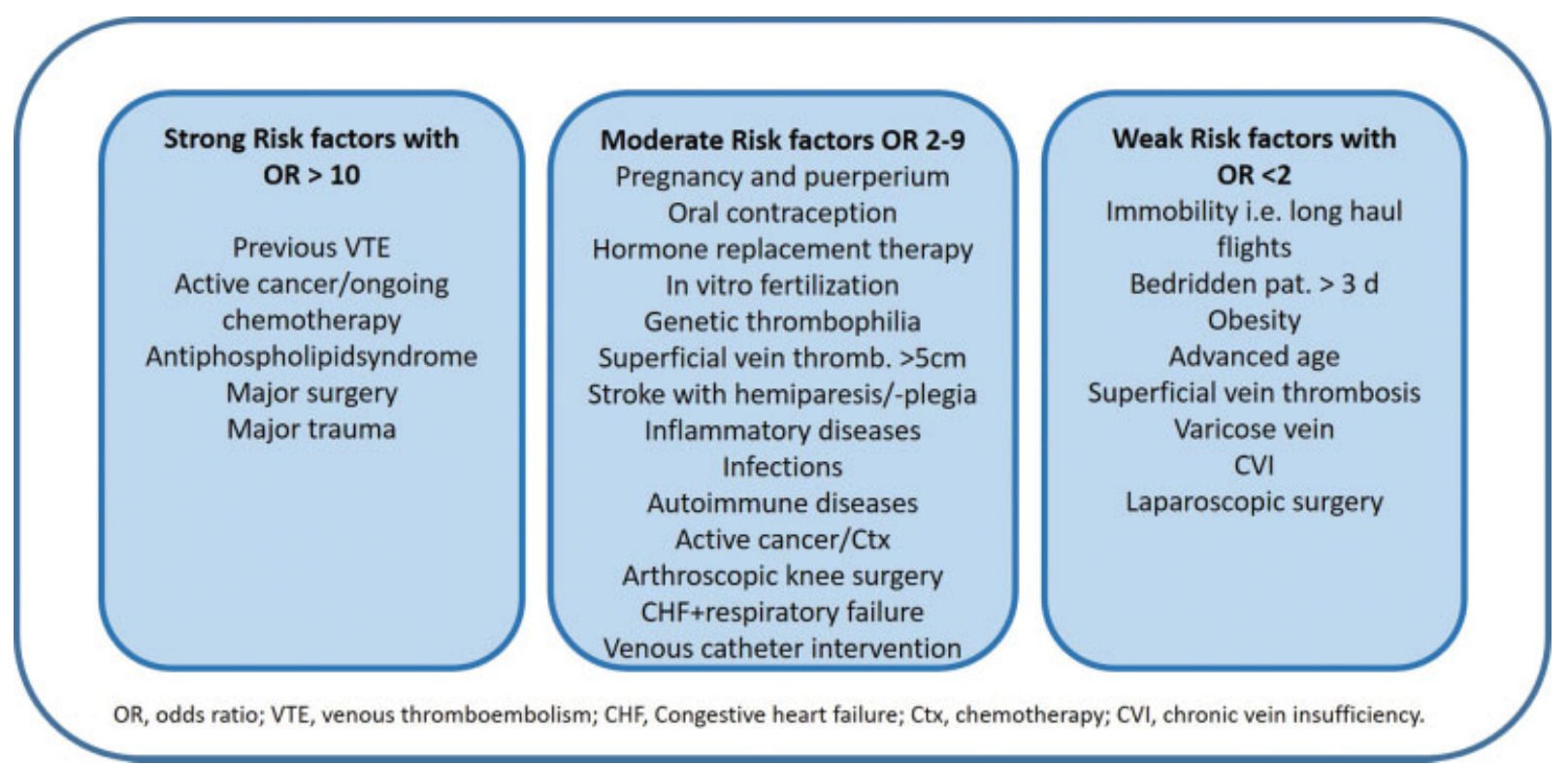

Fig. 1 Risk factors for deep vein thrombosis (DVT) in general population (adapted from Mazzolai et al 2021; Second ESC consensus document of acute DVT). ${ }^{73}$

Table 1 VTE risk factors during pregnancy from Hart et al ${ }^{11}$

\begin{tabular}{|c|c|c|}
\hline $\begin{array}{l}\text { Preexisting risk factors } \\
\text { aOR }(95 \% \mathrm{Cl})\end{array}$ & $\begin{array}{l}\text { Pregnancy-associated risk factors } \\
\text { aOR }(95 \% \mathrm{Cl})\end{array}$ & $\begin{array}{l}\text { Transient risk factors } \\
\text { aOR }(95 \% \mathrm{CI})\end{array}$ \\
\hline $\begin{array}{l}\text { Prior VTE } \\
24.8(17.1-36) \\
\end{array}$ & $\begin{array}{l}\text { Multiple pregnancy } \\
2.7(1.6-4.5)\end{array}$ & $\begin{array}{l}\text { In vitro fertilization } \\
2.7(2.1-3.6)\end{array}$ \\
\hline $\begin{array}{l}\text { Family history of VTE (any relative) } \\
2.2(1.9-2.6)\end{array}$ & $\begin{array}{l}\text { Weight gain }>21 \mathrm{~kg} \\
1.6(1.1-2.6)\end{array}$ & $\begin{array}{l}\text { Ovarian hyperstimulation syndrome } \\
87.3(54.1-140.8)\end{array}$ \\
\hline $\begin{array}{l}\text { Obesity }\left(\mathrm{BMI} \geq 30 \mathrm{~kg} / \mathrm{m}^{2}\right) \\
4.4(3.4-5.7)\end{array}$ & $\begin{array}{l}\text { Preeclampsia } \\
3.1(1.8-5.3)\end{array}$ & $\begin{array}{l}\text { Antepartum immobilization } \\
\text { (strict bed rest }>1 \mathrm{wk} \text { ) with pre-pregnancy } \\
\text { BMI } \geq 25 \mathrm{~kg} / \mathrm{m}^{2} \\
62.3(11.5-337) ; \\
\text { pre-pregnancy BMI }<25 \mathrm{~kg} / \mathrm{m}^{2} \\
7.7(3.2-19)\end{array}$ \\
\hline $\begin{array}{l}\text { Age }>35 \\
1.5(1.1-2.2)\end{array}$ & $\begin{array}{l}\text { Stillbirth } \\
6.2(2.8-14.1)\end{array}$ & \\
\hline $\begin{array}{l}\text { Smoking ( } 10-30 \text { cigarettes/d } \\
\text { prior to or during pregnancy) } \\
2.1(1.3-3.4)\end{array}$ & $\begin{array}{l}\text { Preterm delivery }<37 \text { wk } \\
2.7(2-6.6)\end{array}$ & \\
\hline $\begin{array}{l}\text { Parity } \geq 3 \\
1.0(0.6-1.8)\end{array}$ & $\begin{array}{l}\text { Caesarean section } \\
2.1(1.8-2.4)\end{array}$ & \\
\hline $\begin{array}{l}\text { Anemia } \\
2.6(2.2-2.9)\end{array}$ & $\begin{array}{l}\text { Peripartum hemorrhage }(>1 \mathrm{~L}) \\
4.1(2.3-7.3)\end{array}$ & \\
\hline \multirow[t]{2}{*}{$\begin{array}{l}\text { Varicosis } \\
2.69(1.53-4.7) \\
\end{array}$} & $\begin{array}{l}\text { Postpartum infection } \\
4.1(2.9-5.7)\end{array}$ & \\
\hline & $\begin{array}{l}\text { Transfusion } \\
7.6(6.2-9.4)\end{array}$ & \\
\hline
\end{tabular}

Abbreviations: aOR, adjusted odds ratio; BMI, body mass index; $\mathrm{Cl}$, confidence interval; d, day; VTE, venous thromboembolism. ${ }^{a}$ Exempt from known thrombophilia. All the data are derived from Hart et al. ${ }^{11}$

available. $^{35,36}$ The Royal College of Obstetricians and Gynaecologists (RCOG) guideline recommends a risk score considering preexisting risk factors (i.e., previous provoked VTE, known high-risk thrombophilia, relevant comorbidities, family history in first-degree relative of unprovoked or estrogen-related VTE, low-risk thrombophilia, age, obesity, and more), obstetric risk factors (like preeclampsia in current pregnancy, in vitro fertilization, caesarean section in labor, elective C-section, prolonged labor, and more), and transient risk factors (i.e., OHSS, any surgical interventions, current 
Table 2 VTE risk and hereditary thrombophilias during pregnancy derived from Hart et al $^{11}$

\begin{tabular}{|l|l|l|l|l|}
\hline $\begin{array}{l}\text { Inherited thrombophilic } \\
\text { defect }\end{array}$ & $\begin{array}{l}\text { Incidence in } \\
\text { general population }\end{array}$ & $\begin{array}{l}\text { Estimated RR in pregnancy } \\
\text { OR (95\%Cl) }\end{array}$ & $\begin{array}{l}\text { Absolute risk of VTE, }{ }^{1} \% \text { of } \\
\text { pregnancies (95\% CI) }\end{array}$ \\
\cline { 2 - 5 } & & $\begin{array}{l}\text { Studies with positive } \\
\text { family history }\end{array}$ & Non-family studies \\
\hline Heterozygous FVL & $2.0-7.0$ & $8.3(5.4-12.7)$ & $3.1(2.1-4.6)$ & $1.2(0.8-1.8)$ \\
\hline Homozygous FVL & $0.2-0.5$ & $34.4(9.9-120)$ & $14.0(6.3-25.8)$ & $4.8(1.4-16.8)$ \\
\hline Heterozygous PGM & 2.0 & $6.8(2.5-18.8)$ & $2.6(0.9-5.6)$ & $1.0(0.3-2.6)$ \\
\hline Homozygous PGM & Very rare & $26.4(1.2-559)$ & - & $3.7(0.2-78.3)$ \\
\hline AT deficiency & & $4.7(1.3-17)$ & $3.0(0.08-15.8)$ & $0.7(0.2-2.4)$ \\
\hline Protein C deficiency ${ }^{3}$ & $<0.1-0.6$ & $4.8(2.2-10.6)$ & $1.7(0.4-8.9)$ & $0.7(0.3-1.5)$ \\
\hline Protein S deficiency ${ }^{3}$ & $0.2-0.3$ & $3.2(1.5-6.9)$ & $6.6(2.2-14.7)$ & $0.5(0.2-1.0)$ \\
\hline
\end{tabular}

Abbreviations: AT, antithrombin; BMI, body mass index; $\mathrm{Cl}$, confidence interval; OR, odds ratio; VTE, venous thromboembolism.

aEstimation from multiplying the baseline risk of $0.14 \%$ pregnancies by the RR in non-family studies (observed in family studies).

${ }^{b}$ Dependent on the extent and type of AT deficiency up to $\sim 50$-fold increased risk.

${ }^{C}$ Protein S, protein $C$, and AT deficiency is considered high risk by RCOG R $^{37}$ and $\mathrm{GTH}^{11}$ in case of severe deficiency (PC activity $<50 \%$, PS activity $<40 \%$, AT activity $<60 \%$ ). AT deficiency is considered high risk additionally by ACOG $^{66}$ and SCOG. ${ }^{33}$ All the data are derived from Hart et al. ${ }^{11}$

systemic infection, immobility, dehydration, and additional factors). ${ }^{37}$ If the score exceeds 3 points, one should consider thromboprophylaxis from the first trimester. If the score is 3 points, considering thromboprophylaxis from 28 weeks is recommended and if the score is at least 2 points, postnatal thromboprophylaxis for at least 10 days should be considered.

\section{Hereditary Thrombophilia}

Known thrombophilia increases VTE recurrence risk in pregnant women (-Table 2). Inherited thrombophilia is present in up to half of the cases of pregnancy-associated VTE. The most common inherited genetic risk factors for thrombophilia in the European population are the heterozygous forms of the factor V Leiden and prothrombin 20210 gene mutation, with prevalences of approximately 5 and $2 \%$ of healthy subjects, respectively. ${ }^{11}$ In women who suffered from DVT or PE in pregnancy or puerperium, these genetic disorders can be found much more frequently. In women with or without a positive history for VTE during pregnancy and postpartum, Gerhardt et al reported in 2016 prevalences of $28 \%$ for heterozygous factor $\mathrm{V}$ Leiden, $8 \%$ for heterozygous prothrombin polymorphism G20210A, 2.6\% for homozygous factor $\mathrm{V}$ Leiden, and $8 \%$ for compound heterozygous factor $\mathrm{V}$ Leiden/heterozygous prothrombin mutations. ${ }^{38}$

Similar to the impact of hereditary thrombophilia outside of pregnancy, type of genetic defects and penetrance in the family history of the associated VTE risks vary considerably in pregnant women. For instance, homozygous factor $\mathrm{V}$ Leiden has been shown to increase the relative VTE risk by a factor of 35, whereas heterozygous factor $V$ Leiden carried an eightfold risk increase, ${ }^{39}$ with compound defects somewhere in between. ${ }^{38,40}$ Considering a baseline incidence of VTE of 1 per 1,000 in pregnant women, the absolute risk remains moderate with 3.4 and $0.8 \%,{ }^{38,40,41}$ but, in the presence of additional risk factors, the combined risk may be further increased.

Other thrombophilias are protein C or S deficiency or antithrombin deficiency. Such defects are quite rare in the general population with overall prevalence of $0.2 \%, 0.03$ to $0.13 \%$, or $0.02 \%$, respectively. ${ }^{42}$ The absolute risk for women with protein $\mathrm{C}$ or S deficiency to develop VTE during pregnancy seems to depend on the presence of family history of VTE. Women with coagulation inhibitor deficiency of protein C or S without a personal or family history of VTE are reported to present ante- or postpartum VTE incidences of $0.7 \%$ (95\% CI: 0.3-1.5) and 0.5 (95\% CI: 0.2-1.0), respectively. In contrast, in pregnant women with protein $C$ or $S$ deficiency and a family history for VTE, ante- or postpartum VTE incidences raise to 1.7 (95\% CI: $0.4-8.9)$ and 6.6\% (95\% CI: $2.2-14.7)$, respectively. ${ }^{11}$

Regarding the rare disorder of antithrombin deficiency, the absolute risk estimates are uncertain and vary widely depending on the subtype and extent of the antithrombin deficiency. It has been reported an up to 50 -fold risk increase for VTE in antithrombin-deficient pregnant women, ${ }^{38}$ but several subtypes of antithrombin deficiency have been described with varying risk impacts.

Taken together, hereditary thrombophilias can be roughly divided into:

- "Rare with high VTE risk": homozygous factor V Leiden or homozygous prothrombin gene mutation, compound heterozygosity for these two mutations; severe deficiency of protein C, S, or antithrombin.

- "Common with moderate VTE risk": heterozygous factor V Leiden mutation, heterozygous prothrombin polymorphism.

\section{Acquired Thrombophilia}

Antiphospholipid syndrome (APS) is a thrombophilic disorder that is not inherited and can occur later in life, 
sometimes, but not necessarily in context with rheumatologic diseases such as systemic lupus erythematodes. The diagnosis of APS requires the detection of persisting antibodies in combination with clinical criteria such as vascular thrombosis (arterial or venous) and/or specific pregnancy complications (e.g., recurrent miscarriage, intrauterine fetal death, and preeclampsia). APS is a very heterogeneous syndrome, with risk of thrombosis varying with clinical manifestations and the number, types, and titers of the antibodies. ${ }^{43,44}$ In the absence of clinical criteria, the relevance of APS antibodies is much less clear, as these antibodies also occur in the healthy population. The prevalence of DVT and PE in APS is 39 and $14 \%$ outside of pregnancy and puerperium, respectively. ${ }^{45}$ And although prospectively collected data on the VTE risk of APS in pregnant women are scarce, there is no reason to believe that the combination of procoagulant APS antibodies and physiologic prothrombotic changes in pregnancy is not associated with an excess risk for antenatal or postnatal VTE. In fact, the incidence of VTE up to 6/1,000 women-years has been reported for women with recurrent miscarriage and APS, ${ }^{46}$ and the risk of VTE was associated with an OR of 15.8 (95\% CI: 10.9-22.8) in APS patients during pregnancy. ${ }^{47}$

However, since APS patients with a history of VTE are anticoagulated before pregnancy, they are usually treated with therapeutic doses of low-molecular-weight heparin (LMWH) during pregnancy so that the concept of thromboprophylaxis does not apply here. For the diagnosis of obstetric APS, the occurrence of thrombosis is not mandatory, since this diagnosis is commonly based on previous placentamediated complications or fetal loss. Obstetric manifestations like early miscarriage (before 10 weeks of gestation), late fetal loss (after 10 weeks of gestation), and premature birth among live births occur in 35,17 , and $11 \%$ in APS, respectively, as well as preeclampsia (10\%) and eclampsia (4\%). ${ }^{45}$ A detailed discussion of the management of obstetric APS is beyond the focus of this review, but some insights are provided below.

\section{VTE Risk Assessment and Evaluation for Type of Thromboprophylaxis}

General considerations regarding pharmacological intervention in pregnancy address the efficacy, that is, reduction of maternal VTE risk, the maternal risk of side effects, such as inducing bleeding, local skin reactions, and fetal safety, all being crucial aspects for decision making. Antithrombotic medication can be considered safe and beneficial only when the number of prevented VTE significantly outweighs the expected harms such as bleeding complications. This balance is made more difficult by the fact that each VTE that is not prevented will lead to therapeutic anticoagulation which in turn will increase the bleeding risk much more than a primary prevention strategy with prophylactic doses of anticoagulants.

In pregnant and breastfeeding women, the agent of choice for VTE prevention and treatment is LMWH, with unfractionated heparin (UFH), danaparoid, and fondaparinux being alternatives if LMWH is contraindicated. Vitamin K antagonists are usually not used during pregnancy for thromboprophylaxis. Direct oral anticoagulants are not allowed during pregnancy, as these small molecules pass the placenta and data on fetal safety are very scarce. ${ }^{48}$ The preference of LMWH is explained by the fact that it does not cross the placenta barrier, and LMWH passes into breast milk in only very small amount that is clinically irrelevant because the bioavailability of oral heparin is sparse. ${ }^{32}$ Compared with UFH, LMWH carries lower risks for bleeding, allergies, heparin-induced thrombocytopenia, or osteoporosis. ${ }^{49}$ Moreover, monitoring of drug levels or anticoagulant effect is usually not necessary for prophylactic LMWH and due to longer halflife, once daily dosing is sufficient to achieve adequate plasma levels. Data derived from the nonpregnant population demonstrate a similar clinical efficacy and superior safety profile of LMWH versus UFH and vitamin $\mathrm{K}$ antagonist, ${ }^{50,51}$ which are supported by observational studies in a population of pregnant women. ${ }^{52-55}$ Thus, administration of LMWH rather than UFH is more convenient and feasible and as a consequence, LMWHs have been successfully used in pregnant women for nearly two decades now.

Nonrandomized observational data assume that pharmacological VTE prophylaxis in pregnancy and puerperium is associated with a relative VTE risk reduction comparable with other high-risk situations like extended LMWH prophylaxis after major orthopaedic surgery ${ }^{49,56,57}$ Nevertheless, it is a crucial issue to identify pregnant and postpartum women according to their individual risk level to maximize therapeutic success in preventing VTE events and minimizing harms of side effects of thromboprophylaxis (-Fig. 2).

Thus, several consensus recommendations suggest to consider thromboprophylaxis only when the absolute VTE risk of a specific patient exceeds 1 to $5 \%{ }^{14,33}$ ( - Table 2 ). The broad range is a result from diverging thrombotic risks in pregnancy (5-10-fold increase in comparison to agematched women) versus puerperium (15-35-fold risk increase per day). As such, in the absence of a VTE history or additional predisposing factors, the presence of a nonsevere thrombophilia such as heterozygous F-V mutation alone does usually not require a LMWH prophylaxis. However, in case of a severe thrombophilia or a combination of nonsevere thrombophilias with immobilization, severe obesity, increasing maternal age, or with a personal or familial history of VTE, this risk threshold may be surpassed, making a benefit from LMWH prophylaxis much more likely. On the other hand, the risk of bleeding must be counter balanced. In a review in 2013 including 18 studies with a total of 981 women (predominantly treated with $\mathrm{LMWH}$ ), the risk of severe maternal bleeding in women receiving VTE treatment with therapeutic heparins was estimated to be $1.4 \%$ ( $95 \% \mathrm{CI}$ : $0.60-2.41$ ) antenatally and $1.9 \%$ (95\% CI: $0.80-3.60$ ) within 24 hours after birth. ${ }^{58} \mathrm{~A}$ retrospective observational cohort study was published by Cox et al reporting bleeding events in 172 women who received thromboprophylaxis with $40 \mathrm{mg}$ enoxaparin once daily in $94.8 \%$ of the pregnancies. ${ }^{59}$ Of all deliveries, postpartum hemorrhage was reported in $36.6 \%$ (blood loss: $\geq 500 \mathrm{~mL}$ ) and in $9.3 \%$ (blood loss $\geq 1,000 \mathrm{~mL}$ ), 


\section{Ante- and postnatal Pregnancy risk for VTE without thromboprophylaxis:}

- Retrospective cohort study $n=1104$. Without prophylaxis: $5.8 \%$ VTE (95\% confidence interval [Cl] 3.0-10.6) during pregnancy $+8.3 \%$ VTE (95\%Cl 4.5-14.6) during puerperium, respectively. All women had a personal history of previous VTE. The VTE rate during pregnancy and puerperium even increased if the index event was unprovoked or hormone related (pregnancy or oral contraceptives): $7.5 \%$ (95\%Cl 4.0-13.7) and 15.5\% (95\%Cl 7.7-28.7), respectively (De Stefano 2006).

- Retrospective cohort study with $n=293$ pregnancies of which 197 pregnancies were observed in women with previous VTE but without thrombosis prophylaxis: 8 VTE events accounting to $6.2 \%$ VTE $(95 \% \mathrm{Cl}$ 1.6-10.9). No VTE event occurred in women with thromboprophylaxis ( $n=87$ ). 15 VTEs were observed during puerperium. (Pabinger 2005)

- Prospective cohort study in women with prior VTE and withheld antepartum thromboprophylaxis, postpartum heparin was given four to six weeks postpartum. $\mathrm{N}=125$ pregnancies: $3 / 125$ with VTE: $2.4 \%$ antepartum VTE rate (95\%Cl 0.2-6.9), (Brill-Edwards 2000).

Fig. 2 Overview of selected studies emphasizing on venous thromboembolism (VTE) without venous thromboprophylaxis during pregnancy and puerperium. ${ }^{27,74,75}$

respectively, with the majority of events due to emergency caesarean sections. Four patients needed to be transfused. A systematic review published in 2005 reported assimilated data including 61 studies with 2,603 pregnancies with an indication for prophylactic LMWH and 15 studies with therapeutic LMWH in 174 patients. In the thromboprophylaxis group, significant maternal bleeding occurred in $2 \%$ of the women $(95 \% \mathrm{CI}: 1.5-2.61) .^{52}$ In 2014 , a systematic review, investigating intermediate dosing of LMWH in the long-term treatment of pregnancy-associated thromboembolism, reported a pooled proportion of 0.012 VTE recurrences during long-term treatment (95\% CI: 0.0007-0.035) and found no major antepartum bleeding. Only 1 out of 152 patients developed a recurrent VTE. In the postpartum period, major bleeding was reported as abnormal postpartum bleeding in 0.02 (95\% CI: 0.002-0.05). ${ }^{60}$

Overall, the rate of fatal bleeding complications in pregnant women receiving LMWH seems very low, but solid evidence in this field is missing as most data are derived from retrospective studies on LMWH that did not systematically assess antepartum or postpartum bleeding. In addition, the optimal dose of LMWH prophylaxis especially in the antepartum period is still a matter of debate ${ }^{28}$ and ongoing trials such as the Highlow RCT (www.ClinicalTrials.gov identifier \#NCT01828697) are currently collecting data to solve this issue.

\section{Risk of Recurrent VTE despite Thromboprophylaxis}

There is a substantial paucity of randomized controlled trials for the appropriate dosage for VTE prevention of LMWH in pregnant women. The vast majority of data derive from retrospective cohort studies and only two very small placebo controlled trials. $^{61,62}$ - Fig. 3 summarizes selected studies emphasizing the risk of "break-through thrombosis" (a thrombosis despite adequate thromboprophylaxis) with dif-

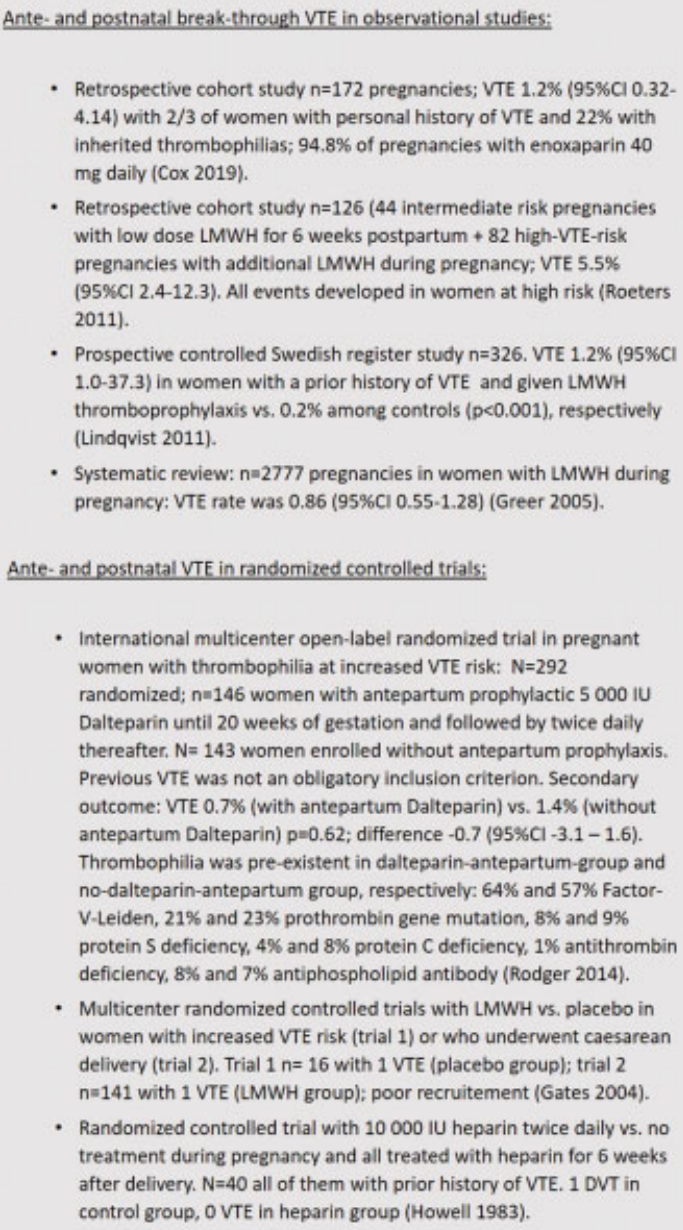

- Prospective controlled Swedish register study $n=326$. VTE $1.2 \%$ (95\%CI 1.0-37.3) in women with a prior history of VTE and given LMWH thromboprophylaxis vs. $0.2 \%$ amone controls $(p<0.001)$, respectively (Lindqvist 2011).

- Systematic review: $n=2777$ pregnancies in women with LMWH during pregnancy: VTE rate was 0.86 (95\%Cl 0.55-1.28) (Greer 2005).

\section{Ante- and postnatal VTE in randomized controlled trials:}

- International multicenter open-label randomized trial in pregnant women with thrombophilia at increased VTE risk: $N=292$ randomized; n=146 women with antepartum prophylactic 5000 IU Dalteparin until 20 weeks of gestation and followed by twice daily thereafter, $N=143$ women enrolled without antepartum prophylaxis. Previous VTE was not an obligatory inclusion criterion. Secondary outcome: VTE $0.7 \%$ (with antepartum Dalteparin) vs. 1.4\% (without antepartum Dalteparin) $p=0.62$; difference -0.7 (95\%Cl-3.1-1.6). Thrombophilia was pre-existent in dalteparin-antepartum-group and no-dalteparin-antepartum group, respectively: $64 \%$ and $57 \%$ FactorV-Leiden, $21 \%$ and $23 \%$ prothrombin gene mutation, $8 \%$ and $9 \%$ protein $S$ deficiency, $4 \%$ and $8 \%$ protein $C$ deficiency, $1 \%$ antithrombin deficiency, $8 \%$ and $7 \%$ antiphospholipid antibody (Rodger 2014).

- Multicenter randomized controlled trials with LMWH vs. placebo in women with increased VTE risk (trial 1) or who underwent caesarean delivery (trial 2). Trial $1 n=16$ with 1 VTE (placebo group); trial 2 $n=141$ with 1 VTE (LMWH group); poor recruitement (Gates 2004).

- Randomized controlled trial with $10000 \mathrm{IU}$ heparin twice daily vs. no treatment during pregnancy and all treated with heparin for 6 weeks after delivery. $\mathrm{N}=40$ all of them with prior history of VTE. 1 DVT in control group, O VTE in heparin group (Howell 1983).

Fig. 3 Overview of selected studies emphasizing on venous thromboprophylaxis during pregnancy and puerperium. ${ }^{52,56,59,61-63,76}$

ferent strategies in heparin prophylaxis of VTE during pregnancy and puerperium. ${ }^{52,56,59,63}$

An updated Cochrane review on VTE prophylaxis during pregnancy and puerperium recently reported on the efficacy of antenatal \pm postnatal heparin prophylaxis in 476 women from four clinical trials. ${ }^{64}$ A wide indication for $\mathrm{LMWH}$ included primary prevention, prevention of pregnancy complications; thus, some women with thrombophilia, known family history of VTE, or caesarean section were at increased risk. In this meta-analysis, the use of LMWH versus no treatment or placebo was associated with a relative VTE risk (RR) of 0.39 (95\% CI: 0.08-1.98). ${ }^{64}$ The review concluded that the evidence of heparin prophylaxis is still very uncertain regarding risk-benefit analysis. Trials with moderate to high bias were observed.

Results from the Highlow study (NCT01828697), which recruited more than 1,100 women between 2013 and 2020, are expected to provide high-quality data on this topic with its international randomized controlled multicenter trial design in the prevention of pregnancy-associated recurrent VTE comparing low-dose LMWH with intermediate-dose LMWH. $^{65}$ 


\section{Guideline Recommendations for Risk- Adapted VTE Prophylaxis in Pregnancy and Puerperium}

Current international guideline recommendations are mainly based on observational and retrospective data and are inconclusive regarding indication, intensity, and duration of thromboprophylaxis in certain risk constellations during pregnancy and puerperium. Despite its long-time and widespread use, optimal dosage of LMWH has not been appropriately evaluated in extended randomized studies. Furthermore, the widespread use of LMWH to prevent non-VTE pregnancy complications may indirectly reduce the VTE risk in these observational studies, impairing adequate risk estimations. So far, only two small randomized controlled pilot trials ( $n=16$ and $n=40$ ) have been conducted in prevention of recurrent VTE. ${ }^{61,62}$

\section{Personal History of VTE}

A personal history of VTE is considered the strongest individual risk factor for VTE recurrence in pregnancy, and all women with prior VTE should be offered counseling and VTE risk assessment prior to pregnancy. In general, the threshold for recommending postpartum prophylaxis is lower than for antepartum prophylaxis since the risk for VTE per day is higher and the duration for complication (i.e., bleeding and burden of daily injections) is shorter.

In accordance with numerous international guidelines, ${ }^{11,14,32,33,37,49,66}$ all women with a personal history of VTE, irrespective of the circumstances of prior VTE occurrence, should be offered postpartum thromboprophylaxis for at least 6 weeks.

For women with a personal history of an unprovoked or hormone-related VTE (i.e., prior pregnancy-related VTE or VTE occurrence in the context of hormonal contraception) and without indication for long-term anticoagulation outside pregnancy, both ante- and postpartum thromboprophylaxis is recommended. If antepartum is indicated, LMWH should be started as soon as possible after pregnancy has been confirmed. However, one should note that some guidelines deviate from this overall consensus. For instance, the RCOG guideline $(2015)^{37}$ suggests to initiate thromboprophylaxis only in the third trimester after the 28th gestational week in all women with prior provoked VTE and without any other VTE risk factors.

Although the far minority of young women with VTE, those who experienced a single prior VTE provoked by a nonhormonal major transient risk factor (i.e., trauma, surgery, immobility) in the absence of hormonal treatment or pregnancy, postpartum-only prophylaxis for 6 weeks is suggested. ${ }^{32}$

\section{Women with Known Thrombophilia}

High-quality data for the reasonable use of antithrombotic prophylaxis in women without a personal history of VTE with known thrombophilia are still limited. Thus, there is no general consensus, and international guideline recommendations differ widely on the topic of thromboprophylaxis in asymptomatic thrombophilia. A reasonable approach could be to grade the types of thrombophilia in different risk categories and consider the family history of VTE as well as additional VTE risk factors in context.

-Table 3 provides an overview over the recent international guideline recommendations for ante- and postpartum thromboprophylaxis for women with thrombophilia in the absence of a personal history of VTE and different risk scenarios (adapted from the Working Group in Women's Health of the Society of Thrombosis and Haemostasis [GTH] guideline 2020). ${ }^{11,41}$ Most guidelines suggest antepartum thromboprophylaxis for pregnant women without a personal history of VTE only in those with both high-risk thrombophilia and a positive family history of VTE. In women with high-risk thrombophilia without positive family history of VTE, antepartum prophylaxis is recommended by the Society of Obstetricians and Gynaecologists of Canada (SOGC), RCOG, American College of Obstetricians and Gynecologists (ACOG), and GTH guidelines, whereas the ASH guidelines favor no prophylaxis in these cases. In women with a low-risk thrombophilia with or without a positive family history of VTE, antepartum thromboprophylaxis is not recommended but has to be considered in the presence of additional risk factors as suggested by SOGC, RCOG, ACOG, and GTH. The threshold for recommendation on postpartum prophylaxis is lower and should be offered to all women with high-risk thrombophilia regardless of a positive family history.

\section{Antithrombotic Prophylaxis for Women with Pregnancy Complications}

In women with pregnancy complications (e.g., recurrent pregnancy loss, fetal loss, preeclampsia, HELLP syndrome, and intrauterine growth restriction), the question frequently arises whether aspirin or LMWH may be of benefit to reduce recurrence of such complications. Particularly in women with APS, aspirin and heparin are widely used. This practice and guideline recommendation is based on only a few intervention studies, and uncertainty regarding benefits and risk remains. ${ }^{67}$ In a recent systematic review, ${ }^{68}$ the effect of heparin (LMWH or UFH), aspirin, or both on live birth rates in women with persistent antiphospholipid antibodies and recurrent pregnancy loss was assessed and included 11 randomized controlled trials. Aspirin alone did not increase live birth rate compared with placebo in one trial of 40 women (RR: $0.94 ; 95 \% \mathrm{CI}$ : 0.71-1.25). One trial of 141 women reported a higher live birth rate with LMWH only than with aspirin alone (RR: 1.20; 95\% CI: 1.00-1.43). Five trials (1,295 women) compared heparin plus aspirin with aspirin only. The pooled RR for live birth was 1.27 (95\% CI: 1.09-1.49) in favor of heparin plus aspirin.

For women with inherited thrombophilia and pregnancy complications, it is unknown whether heparin benefits outcomes such as recurrent pregnancy loss and preeclampsia. ${ }^{69,70}$ Again, in these women, aspirin and LMWH are still widely prescribed. The ALIFE2 study (www.trialregister.nl, ntr3361) including women with inherited thrombophilia 

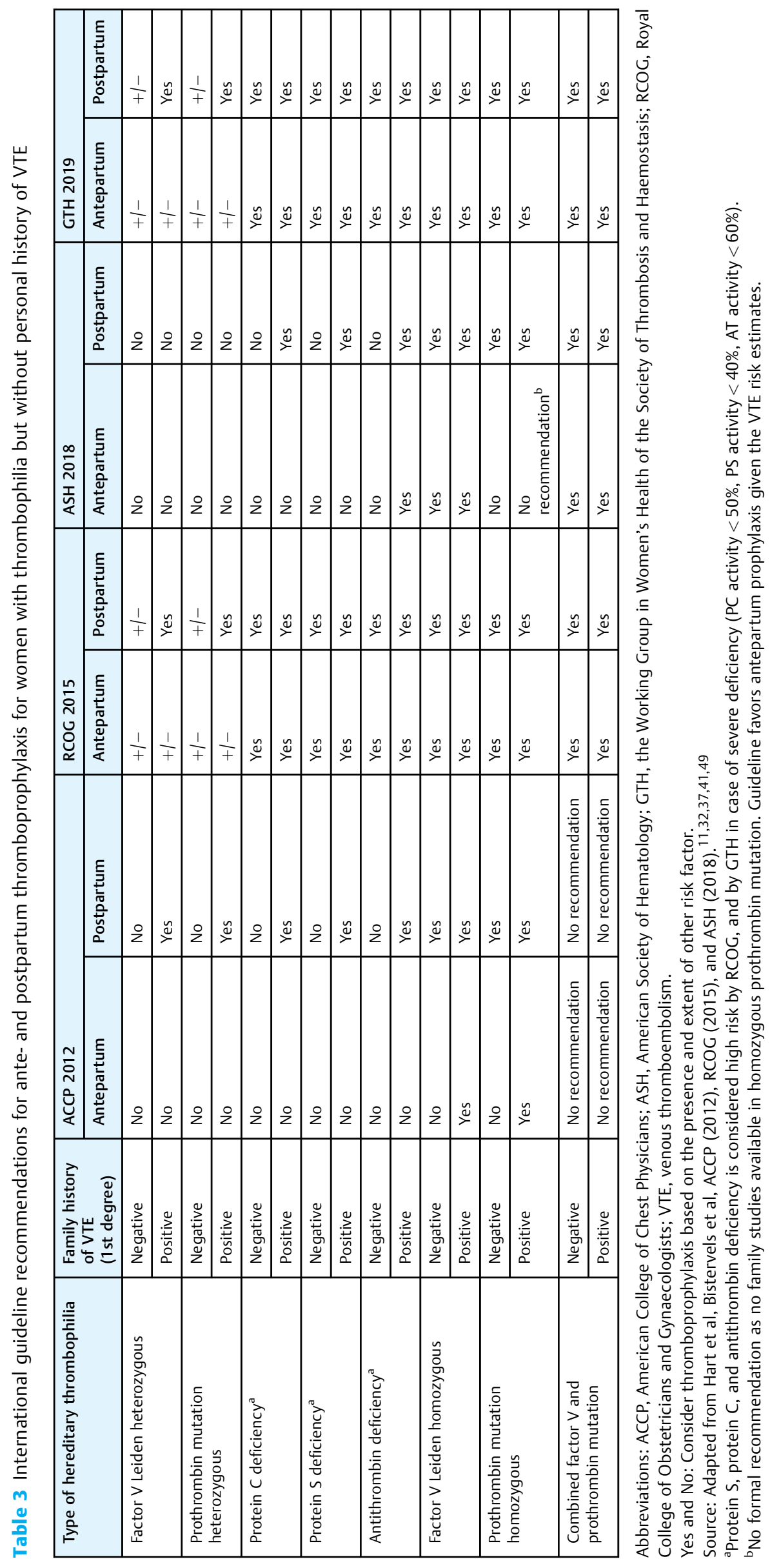
and at least two pregnancy losses has completed recruitment and results are expected in 2022.

Finally, there is ample evidence that aspirin and LMWH do not improve the outcome of pregnancy in women with unexplained pregnancy loss or late placenta-mediated complications. ${ }^{71,72}$

\section{What Is Known About the Subject}

- The risk of developing venous thromboembolism (VTE) is increased and evidence of thromboprophylaxis is sparse during pregnancy and puerperium and with different types of thrombophilia.

- Despite thromboprophylaxis, the risk reduction of VTE in pregnant and lactating women, as well as during puerperium, is comparable with other high-risk prophylaxis indications like extended LMWH prophylaxis following major orthopaedic surgery.

- International guidelines provide recommendations or suggestions for thromboprophylaxis in pregnant or breastfeeding women and in puerperium.

- For thromboprophylaxis during pregnancy complications, the use of LMWH and ASS is frequently discussed.

\section{What This Paper Adds}

- An overview over risk factors and their influence during ante- and postnatal period with a current literature review regarding acquired and hereditary thrombophilia and selected VTE prevention strategies is provided.

- Recurrent thrombosis in pregnancy and puerperium is not zero and the vast majority of data come from two small placebo-controlled trials and retrospective cohort studies.

- Current guideline recommendations for antepartum women are inconclusive regarding thromboprophylaxis in special constellations in women with thrombophilia. They also differ in puerperium, but to a lesser extent.

- In women with APS, a recent overview of indication for heparin and aspirin is discussed, but in women suffering from unexplained pregnancy loss or late placentamediated complications, there is clear evidence that heparin and aspirin do not improve outcomes.

\section{Conflict of Interest}

The authors declare that they have no conflict of interest.

\section{References}

1 Konstantinides SV, Meyer G, Becattini C, et al; ESC Scientific Document Group. 2019 ESC Guidelines for the diagnosis and management of acute pulmonary embolism developed in collaboration with the European Respiratory Society (ERS). Eur Heart J 2020;41(04):543-603
2 Naess IA, Christiansen SC, Romundstad P, Cannegieter SC, Rosendaal FR, Hammerstrøm J. Incidence and mortality of venous thrombosis: a population-based study. J Thromb Haemost 2007;5 (04):692-699

3 Delluc A, Tromeur C, Le Ven F, et al; EPIGETBO Study Group. Current incidence of venous thromboembolism and comparison with 1998: a community-based study in Western France. Thromb Haemost 2016;116(05):967-974

4 Heit JA, Ashrani A, Crusan DJ, McBane RD, Petterson TM, Bailey KR. Reasons for the persistent incidence of venous thromboembolism. Thromb Haemost 2017;117(02):390-400

5 Patel P, Patel P, Bhatt M, et al. Systematic review and meta-analysis of outcomes in patients with suspected deep vein thrombosis. Blood Adv 2020;4(12):2779-2788

6 Roach RE, Lijfering WM, Tait RC, et al. Sex difference in the risk of recurrent venous thrombosis: a detailed analysis in four European cohorts. J Thromb Haemost 2015;13(10): 1815-1822

7 Pomp ER, Lenselink AM, Rosendaal FR, Doggen CJ. Pregnancy, the postpartum period and prothrombotic defects: risk of venous thrombosis in the MEGA study. J Thromb Haemost 2008;6(04): 632-637

8 James AH, Jamison MG, Brancazio LR, Myers ER. Venous thromboembolism during pregnancy and the postpartum period: incidence, risk factors, and mortality. Am J Obstet Gynecol 2006;194 (05):1311-1315

9 Ray JG, Chan WS. Deep vein thrombosis during pregnancy and the puerperium: a meta-analysis of the period of risk and the leg of presentation. Obstet Gynecol Surv 1999;54(04):265-271

10 Jacobsen AF, Skjeldestad FE, Sandset PM. Incidence and risk patterns of venous thromboembolism in pregnancy and puerperium-a register-based case-control study. Am J Obstet Gynecol 2008;198(02):233.e1-233.e7

11 Hart C, Bauersachs R, Scholz U, et al. Prevention of venous thromboembolism during pregnancy and the puerperium with a special focus on women with hereditary thrombophilia or prior VTE - Position Paper of the Working Group in Women's Health of the Society of Thrombosis and Haemostasis (GTH). Hamostaseologie 2020;40(05):572-590

12 Parunov LA, Soshitova NP, Ovanesov MV, Panteleev MA, Serebriyskiy II. Epidemiology of venous thromboembolism (VTE) associated with pregnancy. Birth Defects Res C Embryo Today 2015;105(03):167-184

13 Kourlaba G, Relakis J, Kontodimas S, Holm MV, Maniadakis N. A systematic review and meta-analysis of the epidemiology and burden of venous thromboembolism among pregnant women. Int J Gynaecol Obstet 2016;132(01):4-10

14 Bates SM, Middeldorp S, Rodger M, James AH, Greer I. Guidance for the treatment and prevention of obstetric-associated venous thromboembolism. J Thromb Thrombolysis 2016;41(01):92-128

15 Jackson E, Curtis KM, Gaffield ME. Risk of venous thromboembolism during the postpartum period: a systematic review. Obstet Gynecol 2011;117(03):691-703

16 Sultan AA, West J, Tata LJ, Fleming KM, Nelson-Piercy C, Grainge MJ. Risk of first venous thromboembolism in and around pregnancy: a population-based cohort study. Br J Haematol 2012;156 (03):366-373

17 Kamel H, Navi BB, Sriram N, Hovsepian DA, Devereux RB, Elkind MS. Risk of a thrombotic event after the 6-week postpartum period. N Engl J Med 2014;370(14):1307-1315

18 Abbasi N, Balayla J, Laporta DP, Kezouh A, Abenhaim HA. Trends, risk factors and mortality among women with venous thromboembolism during labour and delivery: a population-based study of 8 million births. Arch Gynecol Obstet 2014;289(02):275-284

19 Say L, Chou D, Gemmill A, et al. Global causes of maternal death: a WHO systematic analysis. Lancet Glob Health 2014;2(06): e323-e333 
20 Creanga AA, Syverson C, Seed K, Callaghan WM. Pregnancyrelated mortality in the United States, 2011-2013. Obstet Gynecol 2017;130(02):366-373

21 Chan WS, Spencer FA, Ginsberg JS. Anatomic distribution of deep vein thrombosis in pregnancy. CMAJ 2010;182(07):657-660

22 Wik HS, Enden TR, Jacobsen AF, Sandset PM. Long-term quality of life after pregnancy-related deep vein thrombosis and the influence of socioeconomic factors and comorbidity. J Thromb Haemost 2011;9(10):1931-1936

23 Wik HS, Jacobsen AF, Sandvik L, Sandset PM. Prevalence and predictors for post-thrombotic syndrome 3 to 16 years after pregnancy-related venous thrombosis: a population-based, cross-sectional, case-control study. J Thromb Haemost 2012;10 (05):840-847

24 Kahn SR, Shrier I, Julian JA, et al. Determinants and time course of the postthrombotic syndrome after acute deep venous thrombosis. Ann Intern Med 2008;149(10):698-707

25 Tick LW, Kramer MH, Rosendaal FR, Faber WR, Doggen CJ. Risk factors for post-thrombotic syndrome in patients with a first deep venous thrombosis. J Thromb Haemost 2008;6(12): 2075-2081

26 Pabinger I, Grafenhofer H, Kyrle PA, et al. Temporary increase in the risk for recurrence during pregnancy in women with a history of venous thromboembolism. Blood 2002;100(03):1060-1062

27 De Stefano V, Martinelli I, Rossi E, et al. The risk of recurrent venous thromboembolism in pregnancy and puerperium without antithrombotic prophylaxis. Br J Haematol 2006;135(03): 386-391

28 Rodger M. Pregnancy and venous thromboembolism: 'TIPPS' for risk stratification. Hematology (Am Soc Hematol Educ Program) 2014;2014(01):387-392

29 Larsen TB, Sørensen HT, Gislum M, Johnsen SP. Maternal smoking, obesity, and risk of venous thromboembolism during pregnancy and the puerperium: a population-based nested case-control study. Thromb Res 2007;120(04):505-509

30 Blondon M, Harrington LB, Boehlen F, Robert-Ebadi H, Righini M, Smith NL. Pre-pregnancy BMI, delivery BMI, gestational weight gain and the risk of postpartum venous thrombosis. Thromb Res 2016;145:151-156

31 Rova K, Passmark H, Lindqvist PG. Venous thromboembolism in relation to in vitro fertilization: an approach to determining the incidence and increase in risk in successful cycles. Fertil Steril 2012;97(01):95-100

32 Bates SM, Greer IA, Middeldorp S, Veenstra DL, Prabulos AM, Vandvik PO. VTE, thrombophilia, antithrombotic therapy, and pregnancy: antithrombotic therapy and prevention of thrombosis, 9th ed: American College of Chest Physicians Evidence-Based Clinical Practice Guidelines. Chest 2012;141(2, Suppl): e691S-e736s

33 Chan WS, Rey E, Kent NE, et al; VTE in Pregnancy Guideline Working Group Society of Obstetricians and Gynecologists of Canada. Venous thromboembolism and antithrombotic therapy in pregnancy. J Obstet Gynaecol Can 2014;36(06):527-553

34 Blondon M, Casini A, Hoppe KK, Boehlen F, Righini M, Smith NL. Risks of venous thromboembolism after cesarean sections: a meta-analysis. Chest 2016;150(03):572-596

35 Dargaud Y, Rugeri L, Fleury C, et al. Personalized thromboprophylaxis using a risk score for the management of pregnancies with high risk of thrombosis: a prospective clinical study. J Thromb Haemost 2017;15(05):897-906

36 Bauersachs RM, Dudenhausen J, Faridi A, et al; EThIG Investigators. Risk stratification and heparin prophylaxis to prevent venous thromboembolism in pregnant women. Thromb Haemost 2007;98(06):1237-1245

37 Nelson-Piercy C, MacCallum P, Mackillop LRoyal College of Obstetricians and Gynaecologists. Reducing the Risk of Venous Thromboembolism during Pregnancy and the Puerperium Green-top Guideline No. 37a;. 2015. Accessed December 30, 2021 at: https:// www.rcog.org.uk/globalassets/documents/guidelines/gtg-37a. pdf

38 Gerhardt A, Scharf RE, Greer IA, Zotz RB. Hereditary risk factors for thrombophilia and probability of venous thromboembolism during pregnancy and the puerperium. Blood 2016;128(19): 2343-2349

39 Robertson L, Wu O, Langhorne P, et al; Thrombosis: Risk and Economic Assessment of Thrombophilia Screening (TREATS) Study. Thrombophilia in pregnancy: a systematic review. Br J Haematol 2006;132(02):171-196

40 Jacobsen AF, Dahm A, Bergrem A, Jacobsen EM, Sandset PM. Risk of venous thrombosis in pregnancy among carriers of the factor $\mathrm{V}$ Leiden and the prothrombin gene G20210A polymorphisms. J Thromb Haemost 2010;8(11):2443-2449

41 Bistervels IM, Scheres LJJ, Hamulyák EN, Middeldorp S. Sex matters: practice 5P's when treating young women with venous thromboembolism. J Thromb Haemost 2019;17(09):1417-1429

42 Middeldorp S. Inherited thrombophilia: a double-edged sword. Hematology (Am Soc Hematol Educ Program) 2016;2016(01):1-9

43 Miyakis S, Lockshin MD, Atsumi T, et al. International consensus statement on an update of the classification criteria for definite antiphospholipid syndrome (APS). J Thromb Haemost 2006;4 (02):295-306

44 Devreese KMJ, Ortel TL, Pengo V, de Laat BSubcommittee on Lupus Anticoagulant/Antiphospholipid Antibodies. Laboratory criteria for antiphospholipid syndrome: communication from the SSC of the ISTH. J Thromb Haemost 2018;16(04):809-813

45 Linnemann B. Antiphospholipid syndrome - an update. Vasa 2018;47(06):451-464

46 Quenby S, Farquharson RG, Dawood F, Hughes AM, Topping J. Recurrent miscarriage and long-term thrombosis risk: a casecontrol study. Hum Reprod 2005;20(06):1729-1732

47 James AH. Pregnancy-associated thrombosis. Hematology (Am Soc Hematol Educ Program) 2009:277-285

48 Beyer-Westendorf J, Tittl L, Bistervels I, et al. Safety of direct oral anticoagulant exposure during pregnancy: a retrospective cohort study. Lancet Haematol 2020;7(12):e884-e891

49 Bates SM, Rajasekhar A, Middeldorp S, et al. American Society of Hematology 2018 guidelines for management of venous thromboembolism: venous thromboembolism in the context of pregnancy. Blood Adv 2018;2(22):3317-3359

50 Green D, Hirsh J, Heit J, Prins M, Davidson B, Lensing AW. Low molecular weight heparin: a critical analysis of clinical trials. Pharmacol Rev 1994;46(01):89-109

51 Nurmohamed MT, Rosendaal FR, Büller HR, et al. Low-molecularweight heparin versus standard heparin in general and orthopaedic surgery: a meta-analysis. Lancet 1992;340(8812):152-156

52 Greer IA, Nelson-Piercy C. Low-molecular-weight heparins for thromboprophylaxis and treatment of venous thromboembolism in pregnancy: a systematic review of safety and efficacy. Blood 2005;106(02):401-407

53 Nelson-Piercy C, Powrie R, Borg JY, et al. Tinzaparin use in pregnancy: an international, retrospective study of the safety and efficacy profile. Eur J Obstet Gynecol Reprod Biol 2011;159 (02):293-299

54 Galambosi PJ, Kaaja RJ, Stefanovic V, Ulander VM. Safety of lowmolecular-weight heparin during pregnancy: a retrospective controlled cohort study. Eur J Obstet Gynecol Reprod Biol 2012; 163(02):154-159

55 Mitić G, Kovac M, Povazan L, et al. Efficacy and safety of nadroparin and unfractionated heparin for the treatment of venous thromboembolism during pregnancy and puerperium. Srp Arh Celok Lek 2010;138(Suppl 1):18-22

56 Lindqvist PG, Bremme K, Hellgren MWorking Group on Hemostatic Disorders (Hem-ARG), Swedish Society of Obstetrics and Gynecology. Efficacy of obstetric thromboprophylaxis and longterm risk of recurrence of venous thromboembolism. Acta Obstet Gynecol Scand 2011;90(06):648-653 
57 Thrombosis Canada. Pregnancy thromboprophylaxis clinical guide. 2021

58 Romualdi E, Dentali F, Rancan E, et al. Anticoagulant therapy for venous thromboembolism during pregnancy: a systematic review and a meta-analysis of the literature. J Thromb Haemost 2013;11(02):270-281

59 Cox S, Eslick R, McLintock C. Effectiveness and safety of thromboprophylaxis with enoxaparin for prevention of pregnancyassociated venous thromboembolism. J Thromb Haemost 2019; 17(07):1160-1170

60 Gándara E, Carrier M, Rodger MA. Intermediate doses of lowmolecular-weight heparin for the long-term treatment of pregnancy thromboembolism. A systematic review. Thromb Haemost 2014;111(03):559-561

61 Gates S, Brocklehurst P, Ayers S, Bowler UThromboprophylaxis in Pregnancy Advisory Group. Thromboprophylaxis and pregnancy: two randomized controlled pilot trials that used low-molecularweight heparin. Am J Obstet Gynecol 2004;191(04):1296-1303

62 Howell R, Fidler J, Letsky E, de Swiet M. The risks of antenatal subcutaneous heparin prophylaxis: a controlled trial. Br J Obstet Gynaecol 1983;90(12):1124-1128

63 Roeters van Lennep JE, Meijer E, Klumper FJ, Middeldorp JM, Bloemenkamp KW, Middeldorp S. Prophylaxis with low-dose low-molecular-weight heparin during pregnancy and postpartum: is it effective? J Thromb Haemost 2011;9(03):473-480

64 Middleton P, Shepherd E, Gomersall JC. Venous thromboembolism prophylaxis for women at risk during pregnancy and the early postnatal period. Cochrane Database Syst Rev 2021;3(03): CD001689

65 Bleker SM, Buchmüller A, Chauleur C, et al. Low-molecular-weight heparin to prevent recurrent venous thromboembolism in pregnancy: rationale and design of the Highlow study, a randomised trial of two doses. Thromb Res 2016;144:62-68

66 American College of Obstetricians and Gynecologists' Committee on Practice Bulletins-Obstetrics. ACOG Practice Bulletin No. 196: Thromboembolism in pregnancy. Obstet Gynecol 2018;132(01): e1-e17

67 Hamulyák EN, Scheres LJ, Marijnen MC, Goddijn M, Middeldorp S. Aspirin or heparin or both for improving pregnancy outcomes in women with persistent antiphospholipid antibodies and recur- rent pregnancy loss. Cochrane Database Syst Rev 2020;5(05): CD012852

68 Hamulyák EN, Scheres LJJ, Goddijn M, Middeldorp S. Antithrombotic therapy to prevent recurrent pregnancy loss in antiphospholipid syndrome - What is the evidence? J Thromb Haemost 2021;19(05):1174-1185

69 de Jong PG, Goddijn M, Middeldorp S. Antithrombotic therapy for pregnancy loss. Hum Reprod Update 2013;19(06):656-673

70 Skeith L, Carrier M, Kaaja R, et al. A meta-analysis of lowmolecular-weight heparin to prevent pregnancy loss in women with inherited thrombophilia. Blood 2016;127(13):1650-1655

71 Rodger MA, Gris JC, de Vries JIP, et al; Low-Molecular-Weight Heparin for Placenta-Mediated Pregnancy Complications Study Group. Low-molecular-weight heparin and recurrent placentamediated pregnancy complications: a meta-analysis of individual patient data from randomised controlled trials. Lancet 2016;388 (10060):2629-2641

72 de Jong PG, Kaandorp S, Di Nisio M, Goddijn M, Middeldorp S. Aspirin and/or heparin for women with unexplained recurrent miscarriage with or without inherited thrombophilia. Cochrane Database Syst Rev 2014;2014(07):CD004734

73 Mazzolai L, Ageno W, Alatri A, et al. Second consensus document on diagnosis and management of acute deep vein thrombosis: updated document elaborated by the ESC Working Group on aorta and peripheral vascular diseases and the ESC Working Group on pulmonary circulation and right ventricular function. Eur J Prev Cardiol 2021:zwab088

74 Pabinger I, Grafenhofer H, Kaider A, et al. Risk of pregnancyassociated recurrent venous thromboembolism in women with a history of venous thrombosis. J Thromb Haemost 2005;3(05): 949-954

75 Brill-Edwards P, Ginsberg JS, Gent M, et al; Recurrence of Clot in This Pregnancy Study Group. Safety of withholding heparin in pregnant women with a history of venous thromboembolism. N Engl J Med 2000;343(20):1439-1444

76 Rodger MA, Hague WM, Kingdom J, et al; TIPPS Investigators. Antepartum dalteparin versus no antepartum dalteparin for the prevention of pregnancy complications in pregnant women with thrombophilia (TIPPS): a multinational open-label randomised trial. Lancet 2014;384(9955):1673-1683 